\title{
Apolipoprotein A-I deficiency
}

INSERM

\section{Source}

INSERM. (1999). Orphanet: an online rare disease and orphan drug data base.

Apolipoprotein A-I deficiency. ORPHA:425

Apolipoprotein Al (Apo A-I) deficiency is a rare lipoprotein metabolism disorder characterized biochemically by complete absence of apolipoprotein Al and extremely low plasma high density lipoprotein (HDL) cholesterol, and clinically by corneal opacities and xanthomas complicated with premature coronary heart disease (CHD). 